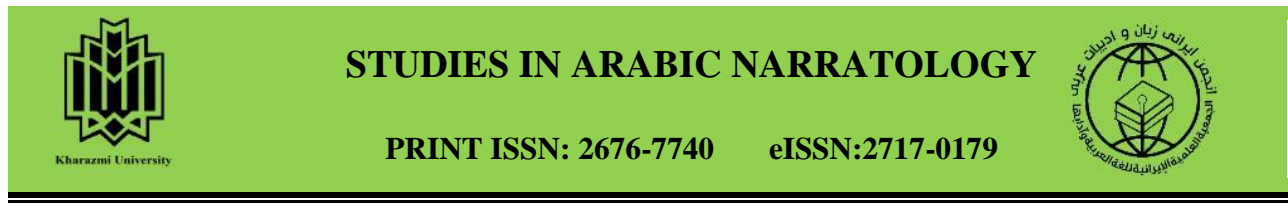

\title{
"The Caravan of Lost" by Badr Shaker Al-Sayyab, between narratology and structure of Arabic poetry
}

\author{
Lara Nabhan Mallak_lara.mallak@lau.edu.lb
}

Professor Advisor of of linguistics at LAU (Lebanese American University)

\begin{abstract}
This research discusses the narrative in the poems of the poet "Badr Shakir AlSayyab" and in his poem "The Convoy of Loss" in particular. The importance of the research is evident in the fact that it deals with the language of a popular Arab poet, and with narratology as a method available in modern poetry. The goal is not only to highlight the poet, his poetry, or the era but to help the readers reach a perception where they can spot differences and boundaries that distinguish the poetic language from the narrative language. This is done by following the two styles in the same text, despite their overlapping, aimed at serving creativity and meaning. As for the methodology of the study, it adopts the behavioral-distributive linguistic research that was brought by the American linguist Bloomfield and applied it in his narratives. This approach has been capable of achieving the goal of the research, as the distribution was an important factor in forming the title, and the behavioral arrangement was essential in the semantic course presented. In order to achieve the desired goals of the adopted approach, the main titles of the research were: 1 the title, 2 the verbs (behavioral study), 3 religious and historical stories, 4 the dialogue. As for the results, this brief study showed that the poem is based on both the narrative and poetry. On the narrative level, the elements of the fictional genre, which are the events, the spatial time frame, the characters, the dialogue, and the narrative voice, are present in most of them. On the poetic level, the poet was unstinting in his use of symbolism and metaphor. However, the segregation of them lies in the segregation of reality and what's been imagined, so the expression teeters between the transmission of the reality and the fabrication of a poetic image that speaks the details of the psychological side. This leads to a correlation between the two and an affection and an influence, as the reality pressures the psychological state until the emotion erupts, whereas the emotion directs its force towards the world in order to influence it. One of the two styles may prevail over the other in some aspects of the text, but it seems that both of them are means and ends simultaneously.
\end{abstract}

Key words: Arabic narratology, Poetics, The Convoys of Loss, Behavioral and Distributive Linguistics, Symbolism, Badr Shakir Al-Sayyab. 
Citation: Mallak, Lara Nabhan .Autumn \& Winter (2020-2021) "The Caravan of Lost" by Badr Shaker Al-Sayyab, between narratology and the poetic text. Studies in Arabic Narratology, 2(3), 53-73. (In Arabic)

Studies in Arabic Narratology, Autumn \& Winter (2020-2021), Vol. 2, No.3, pp. 53-73 Received: November 21, 2020; $\quad$ Accepted: March1, 2021

CFaculty of Literature \& Humanities, University of Kharazmi and Iranian Association of Arabic Language \& Literature. 


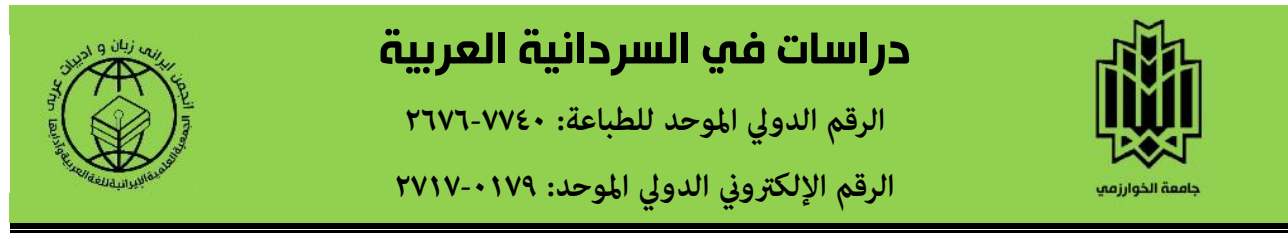

\section{"قافلة الضّياع" لبدر شاكر السيّاب، بين السرّدانيّة وبناء النّصّّ

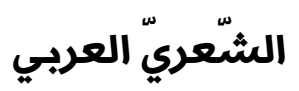

lara.mallak@lau.edu.lb

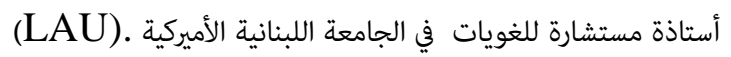

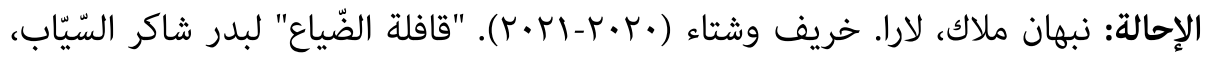

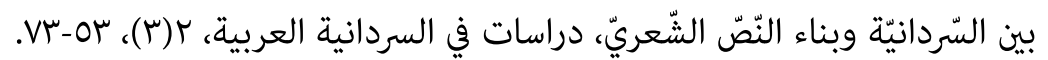

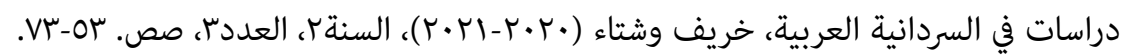

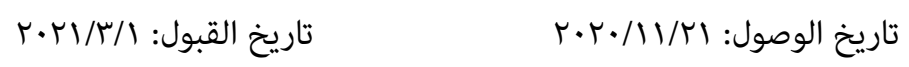

ه كلية الآداب والعلوم الإنسانية بجامعة الخوارزمي والجمعية العلمية الإيرانية للغة العربية

يدور هذا البحث حول فكرةٍ مركزيّةٍ أولى هي السّردانيّة في قصائد الشّاعر بدر

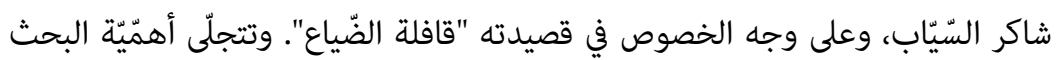
في كونه يتناول لغة شاعرٍ عربيٍ ذي شهرةٍ واسعة، ويتناول السّردانيّة بوصفها أسلوبًا

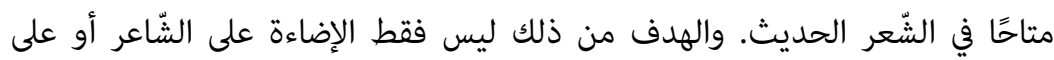

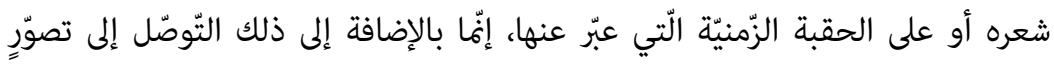

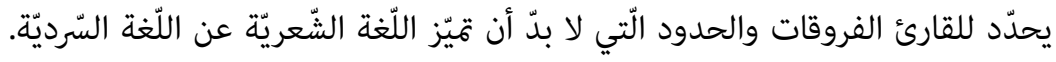
ويكون ذلك من خلال تتبّع الأسلوبين في النّصّ الواحد على الرّغم من تداخلهما خدمةً 
للإبداع وللمعنى. أمّا في منهجيّة الدّراسة، فيعتمد البحث الألسنيّة السّلوكيّة التّوزيعيّة التّي أتى بها العالم اللّغويّ الأميركيّ بلومفيلد، وطبّقها في نصوصِ سرديّة. ويبرز

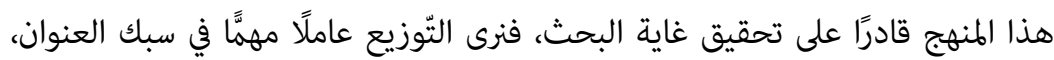

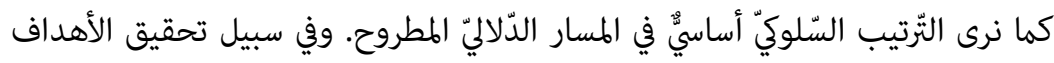
المرجوّة ضمن المنهج المعتمد، جاءت عناوين البحث الأساسيّة: العنيّة العنوان، ب الأفعال (دراسة سلوكيّة)، ب القصص الدّينيّة والتّاريخيّة، ع الحوار.أمّا في النّائج، فقد أظهرت هذه الدّراسة المختصرة ارتكاز القصيدة على السّردانيّة والشّعريّة معًا. على المستوى السّرديّ مل تغب عناصر النّوع القصصيّ بأغلبها، وهي الأحداث، والإطار الزّمانيّ المكانيّ، والشّخصيّات، والحوار، والصّوت السّرديّ. وعلى المستوى الشّعريّ ملم يبخل الشّاعر بالرّمزيّة وبالمجاز. بَيْد أنّ الفصل بينهما يكمن في الفصل بين الواقع والمتخيَّل، فيتأرجح

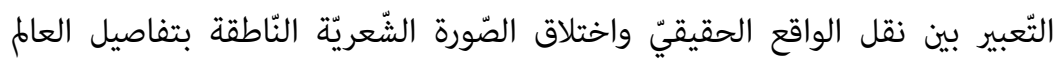

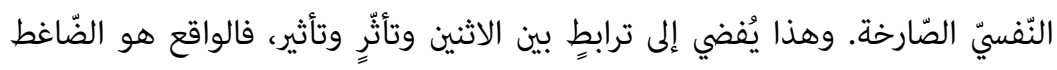

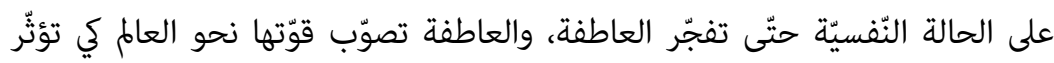
فيه. وقد تكون الغلبة لأحد الأسلوبين على حساب الآخر في بعض جنبات النّصّ، لكن يبدو أنّ كلًّ منهما وسيلةٌ وغاية في آنٍ معًا.

الكلمات الدليلية: السّردانيّة العربيّة، الشّعريّة، قافلة الضّياع، الألسنيّة السّلوكيّة التّوزيعيّة، الرّمزيّة. 
برز بدر شاكر السّيّاب شاعرًا محدثًا استطاعت نصوصه تحقيق شهرةٍ واسعةٍ لأسبابٍ عديدةٍ

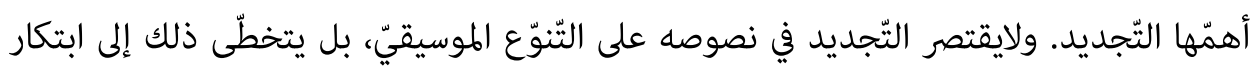

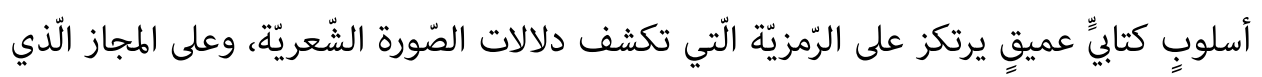

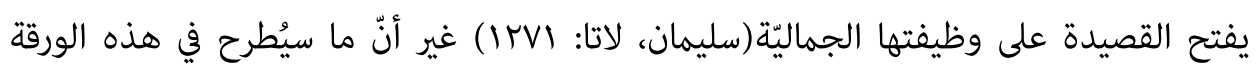
البحثيّة يراوح بين الشّعريّة في قصائد السّيّاب - وتحديدًا قصيدته "قافلة الضّياع"- والسّرديّة. ويعود سبب طرح هذه القضيّة إلى أنّ هذا الشّاعر اعتمد السّرد في كثيرٍ من نصوصه (الحاوي، يُّاب

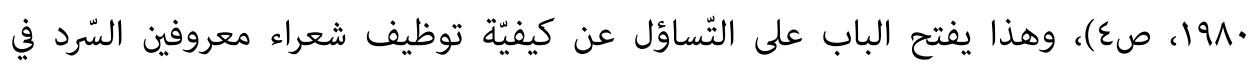

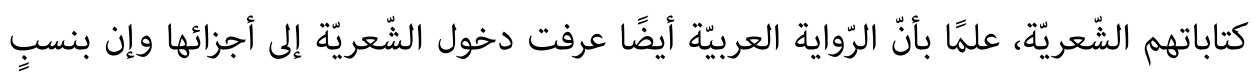
متفاوتةٍ بين الرّواية والأخرى وذلك من خلال تركيز بعض الرّوائيّن على التّعبير الجماليّ والصّور

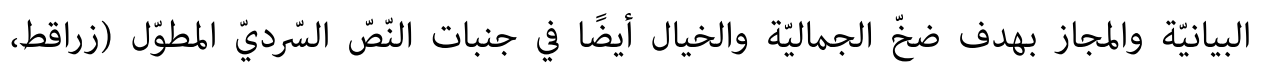

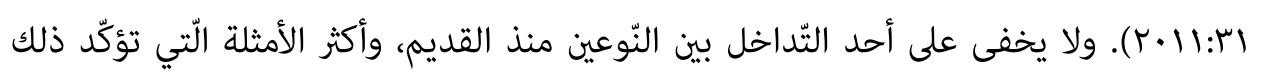
بشكلٍ جليّ، الملاحم التّي تعتمد القالب الشّعريّ في الكتابة السّرديّة، وقد رأى بعض النّقّاد في

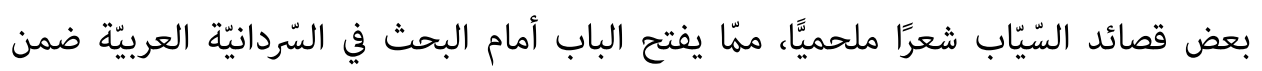

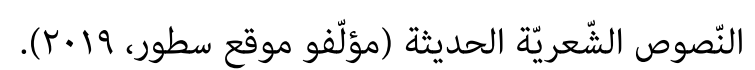

ولعلّ أهمّ ما يجب طرحه عند البحث في سرديّةٍ تقتحم قصيدةً شعريّةً هو التّقاطع بين

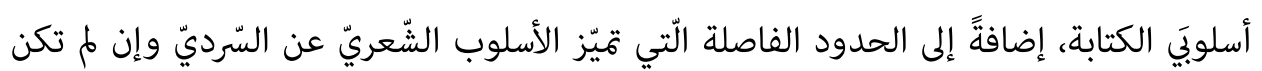
هذه الحدود قاطعةً حادّة. ولتحقيق هذا الفصل وتوضيح تفاصيله إعتمد الباحث في هذا البحث المختصر الألسنيّة السّلوكيّة التّوزيعيّة منهجًا، وهي منهجٌ ابتكره بلومفيلد في التّحليل اللّغويّ وفي دراسة النّصوص مستندًا إلى النّظريّة السّلوكيّة في علم النّفس. أسئلة البحث: (n

ويكون سؤال هذا البحث متمثّلًا في الأسئلة التّالية: كيف يظهر التّركيب السّرديّ في قصيدة السّيّاب هذه؟ مئد كيف تتبدّى الصّلات والحدود الفاصلة بين السّرديّة والشّعريّة فيها؟ 
كيف تظهر وظيفة السّرد في تشكيل بنية هذا النّصّ الشّعريّ؟ أمّا في أهداف البحث، فهي التّعمّق الأكثر في أشكال السّرديّة الّتي يطرحها هذا هذا الشّاعر في

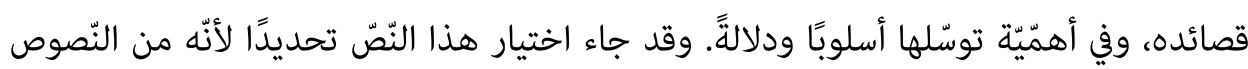
التّي توضح هذه التّقنيّة عند الشّاعر وتسهم في تحقيق الهدفّ المرجوّ من البحث. إنّ محاولة الكشف عن إجاباتٍ وافيةٍ حول هذه المسائل الأساسيّة تتطلّب تقديم مقاربةٍ موضوعيّةٍ قدر الإمكان لنصّ "قافلة الضّياع"، كما تحتاج إلى خلق منهجيّةٍ واضحة المعالم تُبِرِ

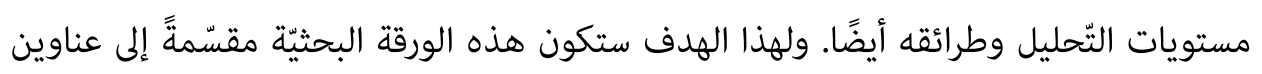
عريضةٍ نجدُها توضّح في تفاصيلها عناصر الشّعريّة والسّرديّة، إضافةً إلى إبراز معالههما وأهمّيّة الدّمج بينهما في سبيل تحقيق الجماليّة وفي سبيل التّعبير الدّلاليّ، وهذه العناوين هي:

1- (- العنوان

r- الأفعال (دراسة سلوكيّة) ب- القصص الدّينيّة والأحداث التّاريخيّة ع- الحوار

خلفية البحث

تشير عملية البحث التي أجراها الباحث إلى أنّ موضوع هذا المقال جديد وم يتصدَّ له أحد حتى الآن غير أنّ هناك مصادر كُتبت في مجال الألسنية والسردية الشعرية فنشير إلى أهمّها هنا وهي كما يلي: -حسن كازار،(1) • (ب)، اللسانيات الاجتماعية في الدراسات العربية الحديثة، دار الرافدين.

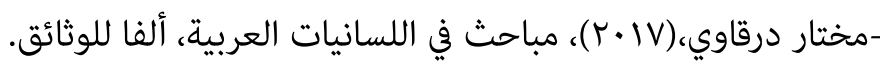

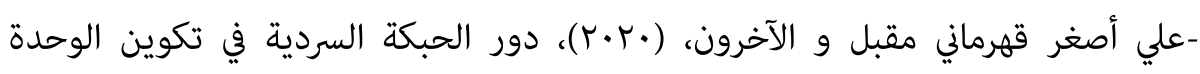

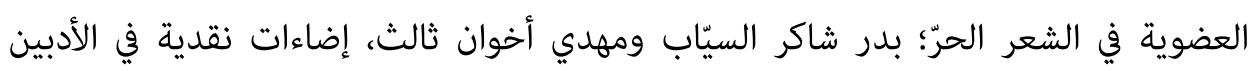

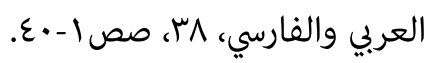

r-دراسة السردية في قصيدة "قافلة الضياع"

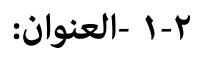


العنوان في أيّ نصِّ هو نظامٌ سيميائٌّ له أبعادٌ دلاليّة، وهو مختصرٌ يضبط الدّلالة

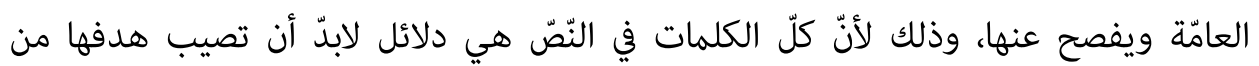
المعنى أي أن تؤدّي وظيفتها التّعبيريّة(بارت، IVM I IV ). ونستطيع في هذا النّصّ أن نقسّم العنوان إلى قسمين واضحين، لنشرح بعدها كلّ جزءٍ ونحلّله دلاليَّا، ثمّ سنقيم الرّبط بينهما في

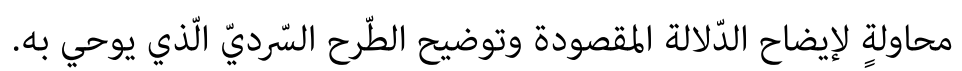

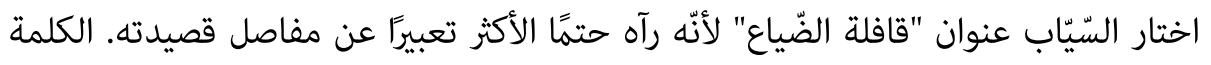
الأولى منه وهي القافلة، توحي بالسّفر وبقيام مجموعةٍ من الأفراد بالانتقال معًا من مكانٍ إلى

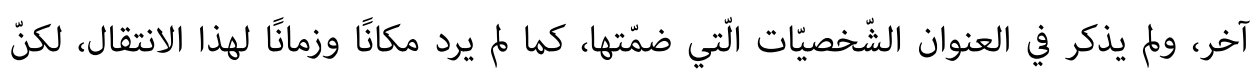
الحديث عن قافلةٍ يشير إلى جماعةٍ وليس إلى فردٍ واحد. ولا بدّ أنّ هذه الجماعة ستظهر في تفاصيل القصيدة. أمّا الجزء الثاني من العنوان، فهو اسمٌ أيضًا، لكنّه مصدر، أي أنّه اسمّ يحمل معنى الفعل من دون وجود تحديد زمانٍ له ومن دون ذكر الفاعل. وهذا المصدر هو "الضّياع"، وهو فقدان

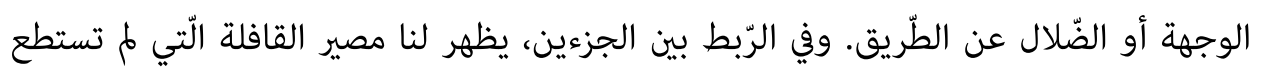

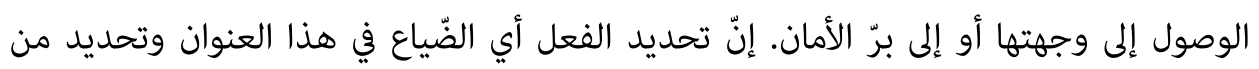
يقوم بالفعل أي القافلة، يوحي بزمانٍ ومكانٍ أيضًا لابدّ أنّ الفعل وقع ضمنهما. وهذا الفيدا الفعل ليس وليد زمنٍ قصيرٍ، بل هو ممتدُّ زمنًا لأنّ الانطلاق في الرّحلة، والضّياع بعدها يتطلّبان سيرًا

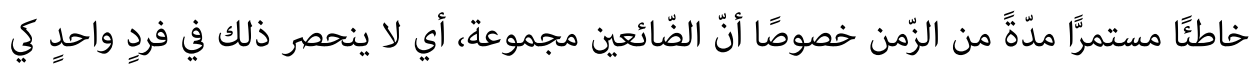

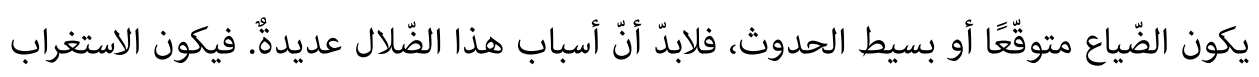
في عدم قدرة أيّ جزءِ من هذه المجموعة على استكشاف الطُّيق، واكتشاف مكامن الخلل في توجيه الجماعة وتحقيق الوصول. وهذه التّفاصيل الكثيرة التّي تطرحها كلمتان اثنتان تدلّان

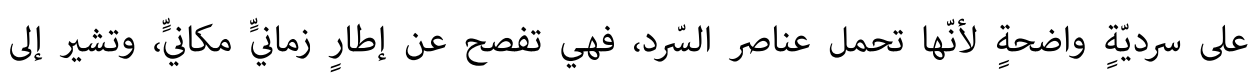
تسلسلٍ حَدَثِيّ، كما تفضح سمات الشّخصيّات الّتي تظهر بمظهر الضّعف، وعدم القدرة على القيادة وربمّا على الاتّحاد في سبيل تحقيق الحاجة الجماعيّة.

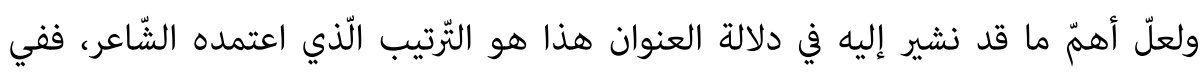

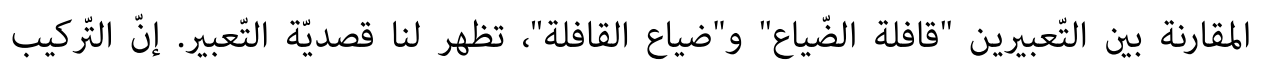


اللّغويّ يوحي بأهمّيّة القافلة بالنّسبة للمؤلّف، لأنّ التّقديم دليل أهمّيّة عند المتكلمّ، وقد ذكر النّقّاد البُعد الدّلايّ لموقع الكلمة بالنّسبة للألفاظ المجاورة لها في السّياق، ويكون ترتيب هذا لهّل

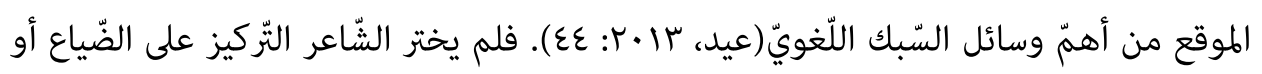
ربمّا سرد مراحله مفصّلًا، بل قصد التّركيز على القافلة التّي تعاني من هذا الضّياع. هذا يدلّ على آلى

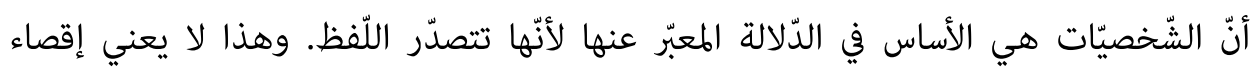
السّرديّة، لكنّه أيضًا قد يعني أنّ الأهمّ ليس طرح الحدث بل وصف المتفاعلين معه أو المسبّبين

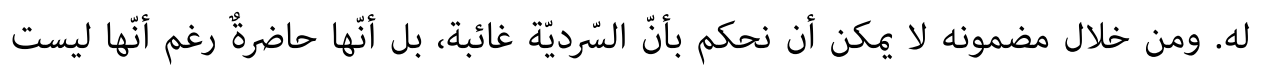

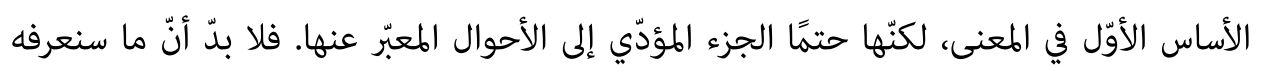

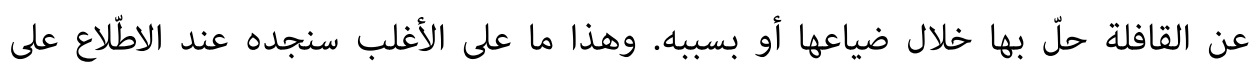

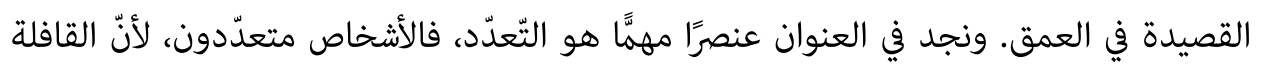

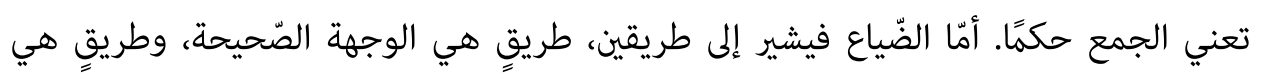

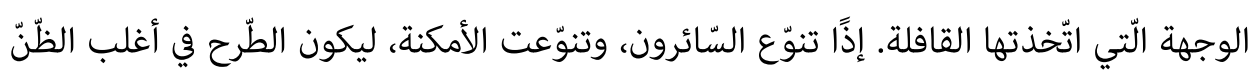

متشعبًا.

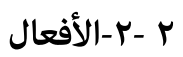

ترتكز السّرديّة على الحدث، ويأتي الإطار الّذي يقع الحدثُ ضمنه مكمّلًا أو مؤثبّرًا فيه، كما

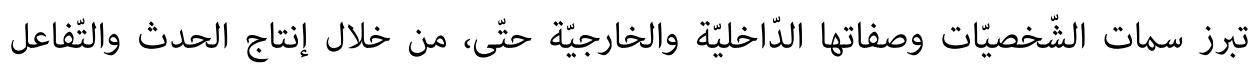

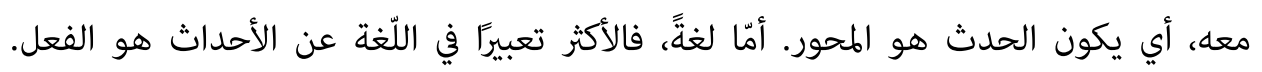

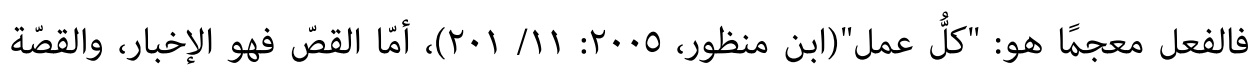

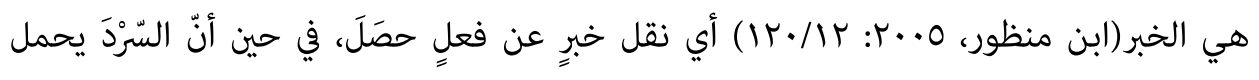

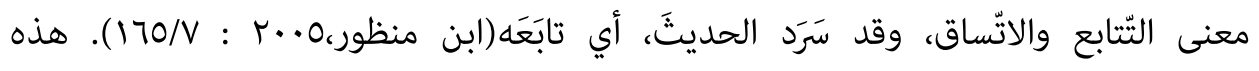
التّعريفات المعجميّة تحدّد بدقِّة مفهوم السّرديّة الّذي يرتكز على تتابع الأفعال أي الأحداث التّي

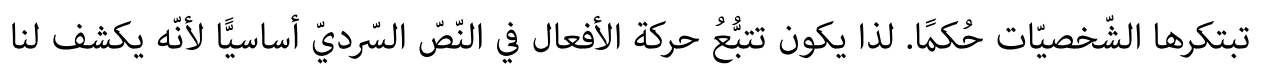
التّسلسل في الطُّح، كما يحدّد التّفاعلات القائةة بين صانعي الأحداث، ليقيم تصوّرًا ممنهجًا للقارئ حول تركيب النّصّ وصولًا إلى الخاتمة المرتقبة. 
لعلّ المقاربة تختلف في دراسة نصِّ يندرج في إطار الشّعر، لكنّ دراسة السّرديّة التّي تقتحم

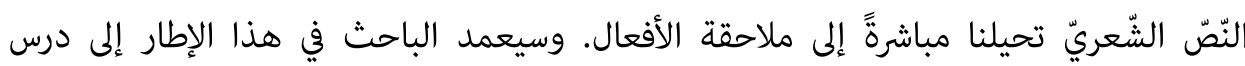

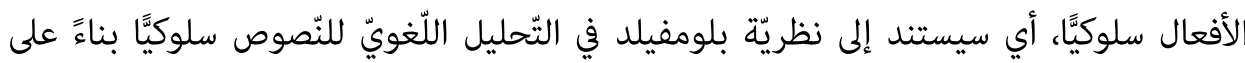
السّلوكات البارزة فيه، ليكون النّّ ميثابة الحدث الكلاميّ في تقسيم السّلوكات وتفصيلها ضمن السّياق المطروح. وتقوم السّلوكيّة على تحليل الأفعال على أنّها الاستجابات الّتي تأتي ردّاتِ فعلٍ على مثيراتٍ معيّنة، ويعود ذلك إلى النّظريّة السّلوكيّة في الدّراسة النّفسيّة الّتي ترى في السّلوك استجابةً لمثيرٍ خارجيّ. وتتتابع المثيرات والسّلوكات في النّصوص بحسب هذه النّظريّة، فنجد أنّ النّ

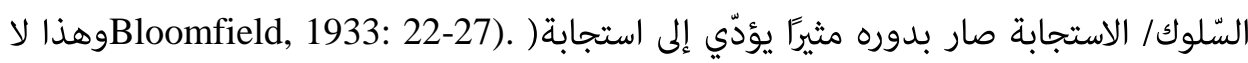
يعني دراسة الفعل الكلمة فقط بل ما دلّ عليه أيضًا وما حمل معناه، أي دراسة المصادر وأسماء الأفعال واسم الفاعل واسم المفعول، وغيرها... وقد استفاد محلّلو النّصوص من النّظريّات في علم النّفس، وتأتي اللّسانيّة السّلوكيّة في الدّراسات خير دليلٍٍ على ذلك. وفي النّر سلوكيًّ إلى هذه القصيدة ضمن هذا البحث، ستعمد هذه الورقة إلى تقسيم النّصّ خطّين متقابلين من السّلوكات التّي تفصل بوضوحٍ أكثر بين الشّعريّة والسّرديّة قدر المستطاع من دون ادّعاء الفصل الكامل حدّ القطع بينهما. وما لا بدّ من ذكره قبل ذلك مبّ أنّ السّلوكيّة لأنّها تصحّ في تتبّع الفعل وردّات الفعل، تصحّ في تتبّع السّرديّة التّي يكشفها النّصّ. وهذه السّرديّة

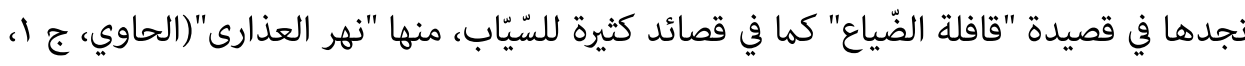

بناءً عليه سيأتي الفصل بين السّلوكات بحسب فاعلها، أي سيكون الخطٌ السّلوكّيّ الأوّل اللّني نحدّده لشخصيّاتٍ حقيقيّةٍ أو نجد في الواقع شبيهاتٍ لها، بينها سيكون الخطٌ الثّاني لسلوكاتٍ من نتاج فاعلين متخيَّلين مجازيين ضمن النّصّ. وهذا التّقسيم سيفضي إلى تحديد النّقل الواقعيّ

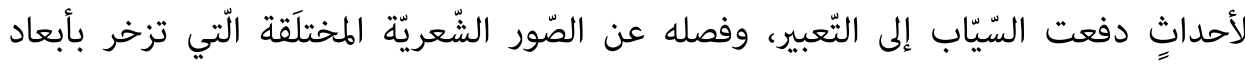
جماليّةٍ وعاطفيّةٍ وشعريّة. وخلال هذا التّقسيم سيكون التّركيز أيضًا على تبدّل الصّورة الشّعريّة مع تتابع السّرديّة بشكلِ موازٍ قائمِ على التّأثرّ والتّأثير.

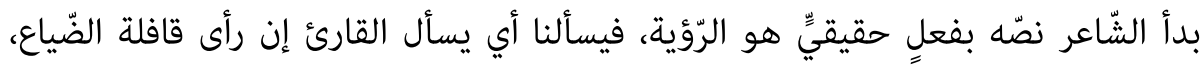

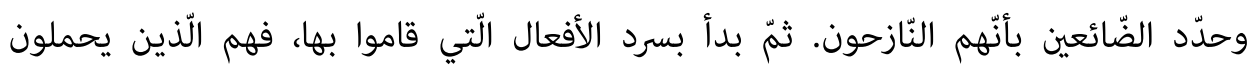


وجعهم، ويتحمّلون خطايا العالم، وهم الّذين ينزفون من الدّاخل وإن مُ يظهر عليهم الدّم، وهم السّائرون إلى الوراء، ممّا يوضح فعل الضّياع على أنّه معاكسة الطّريق، والسّير عكسها، ويكون السّير إلى الوراء لكن عبر التّاريخ لدفن هابيل، أي لدفن الضّحيّة، والدّفن طقسٌ أساسيٌّ لرحمة

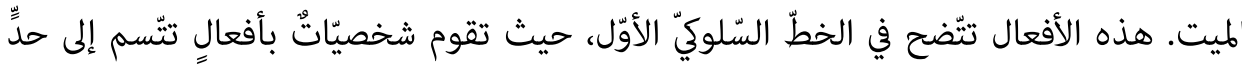

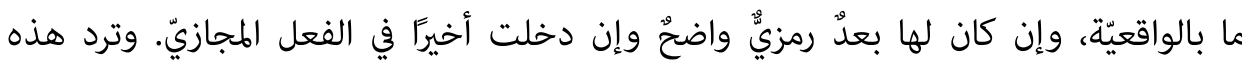

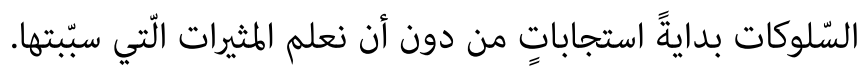

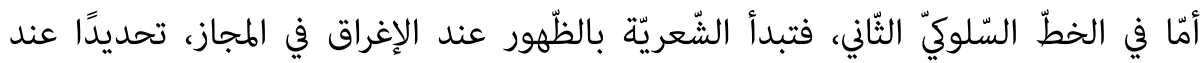

إعطاء السّماء والنّجوم صفاتٍ وأفعالًا بشريّة، فيكون الصّياح والنّداء منهما غضبًا من قابيل. ثمّم، وضمن الخطّ السّلوكيّ الأوّل، يستحضر السيّاب هابيل، ليسرد أفعاله، هو الّذي ينام في خيام اللّاجئين، ينام ضعيفًا بسبب السّلّ. بعدها يأتي الجوع في هذه القصيدة، ليذكره السّيّاب

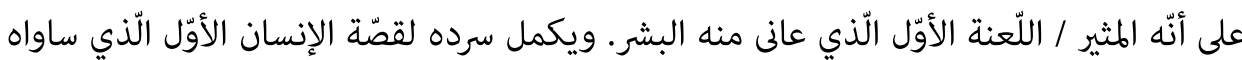
الجوع بالحيوان، وحوّله إلى الدّركِ الأسفل، ثمّ ما رفعه إلّا الرّغيف. ويتابع في سرد الضّياع هذا ليصل إلى ذكر احتلال اليهود لفلسطين، فقد ألقى اليهود المراسي في حيفا، كان هذا سلوكيًّ المثير الّذي أدّى إلى استجابة النّاس المضطهدين الّّاين، وحتّى الموتى منهم، جحظت عيونهم. وضمن الخطّ السّلوكيّ الثّاني القائم على المجاز والتقاط الصّورة الشّعرية، يصف اللّيل الحزين الّذي يجهض الحياة، وهذا لا يعني الانفصال عن سلوكات الخطّ الأوّل، فالحالة الشّعوريّة مرتبطةٌ بما يحدث من أفعالٍ واقعيّة. تصير الحياة مأرجحةً بين الموت والعدم، وتصير الحدود بين

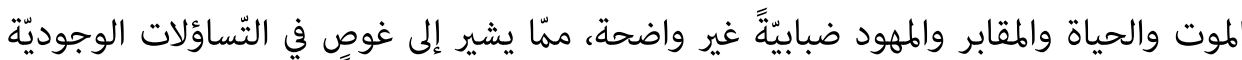

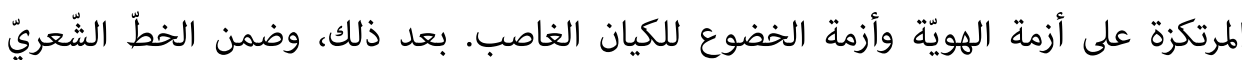
نفسه، يصف لنا صراخ النّار في المزارع والمنازل والطّرقات، فهي النّضار الخالص النّظيف من كلّ شائبة. وتستمرّ النّار في تتبّع لصوص الأرض، وتحفر النّور وتصنع له بابًا. ليعود إلى الخطّ الأوّل، وتحديدًا مع شخصيّة المسيح الّذي يستعين بثوبه وبدمه كي يسدّ

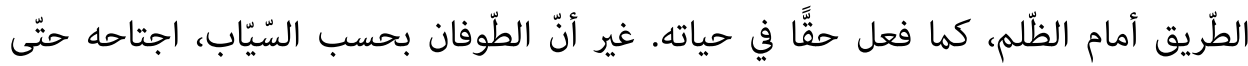

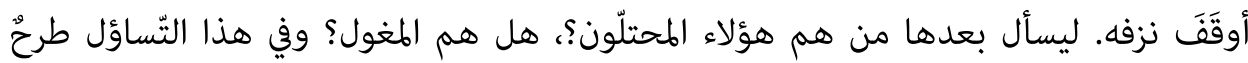


سرديٌّ يهدف إلى التّذكير بأفعال المغول وأثرهم السّلبيّ في بلاد العرب. ويذكّرنا بخيول العرب

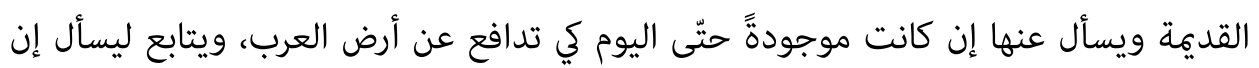

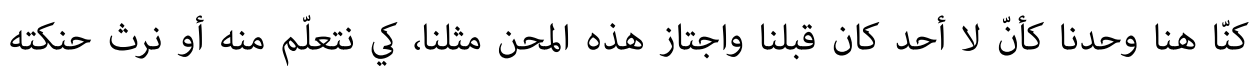

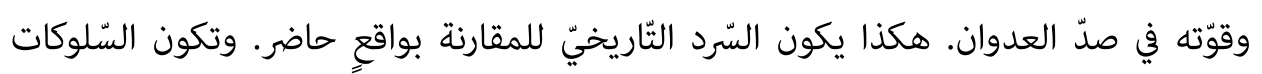
الرّاهنة لا تشبه السّلوكات القديمة عند الحروب، وكأنّ الأحداث التّي تُسرَّد حولنا اليوم أي في زمن الاحتلال لا تليق بما كنّا عليه سابقًا.

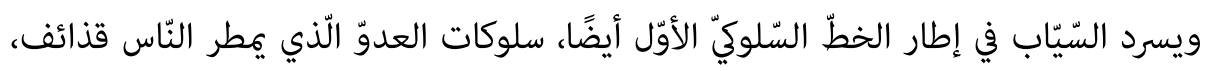

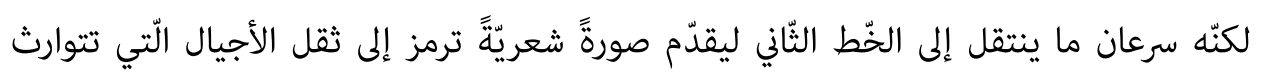
المحن، فيصوّر العربيّ يحمل أباه، أي الجيل القديم، على ظهره، ويحمل جنينه، أي الجيل الآتي، في

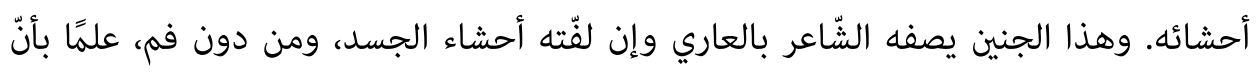

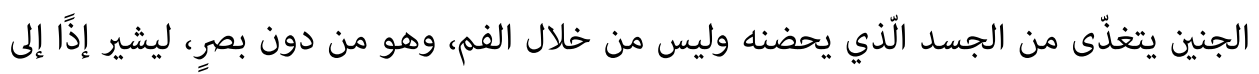
جيلٍ عاجزٍ قبل أن يولد، وهذا الجنين شبيه الجرس لأنّه يوقظ في الشّاعر صوتَه وصداه معًا حتّى دهِ يحسّ بالسّلام. وبذلك يراه من خلال الدّم، بلا عظامٍ وبلا أبٍ وبلا حيفا، أي كأنّه يفقد ذاكرته

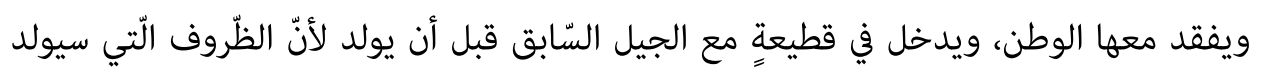
فيها ستؤدّي كما يرى السّيّاب إلى هذه القطيعة. ولا تكون هذه السّلوكات منفصلةً عن سابقاتها

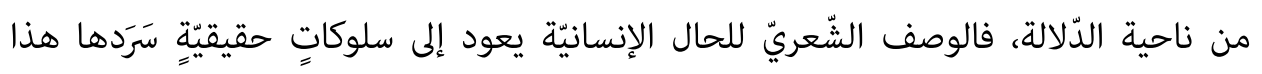

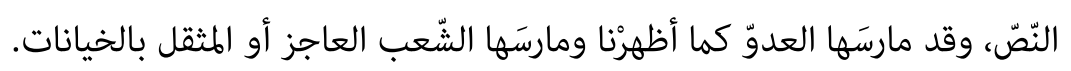
ويدخل من جديدٍ في السّرديّة أي في الخطٌ الأوّل، ليسرد هربَه هو الّّني تُلقى عليه

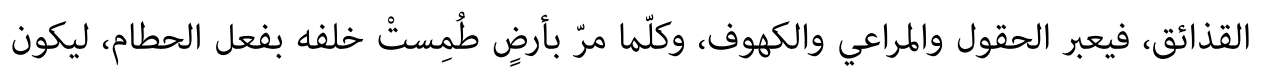

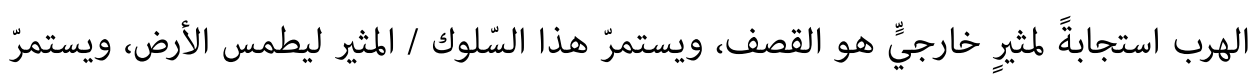

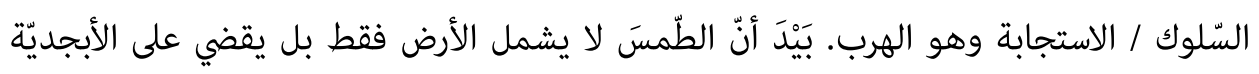

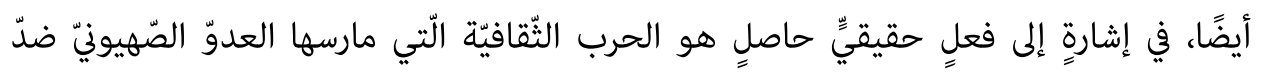

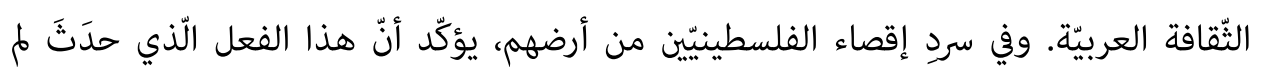
يشمل الإقصاء من الأراضي، بل امتدّ إلى إخراج ابن الأرض من الحياة الآدميّة التّي يستحقّها كلّ إنّاء

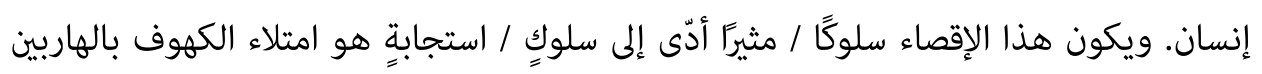


الجائعين وموتهم من دون أن يتركوا لأطفالهم ما له قيمةٌ تُذكر، ولعلّ للكهوف رمزيّة التّخلّف

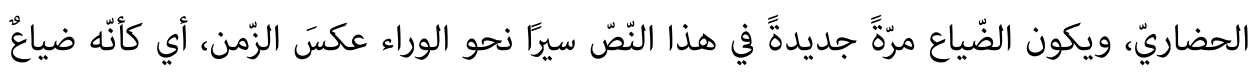

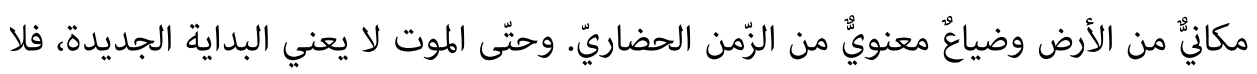

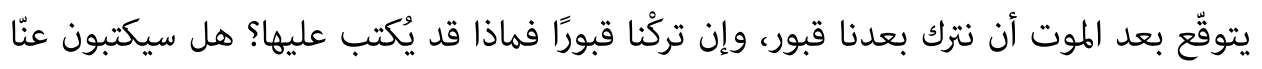

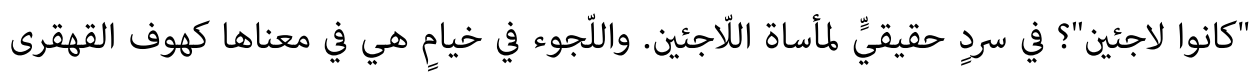

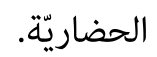

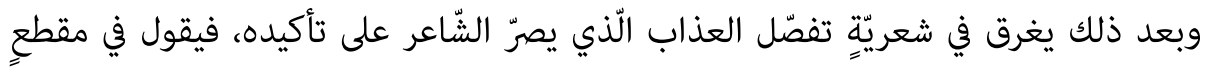

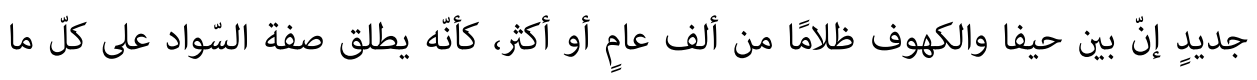

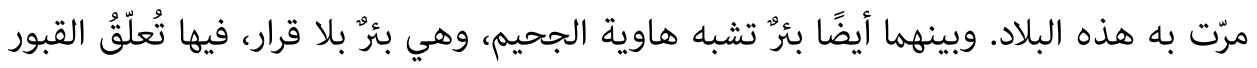

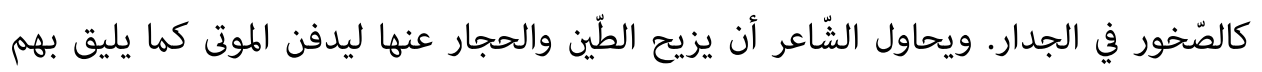

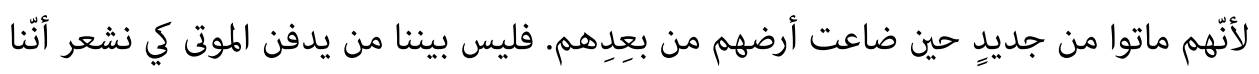

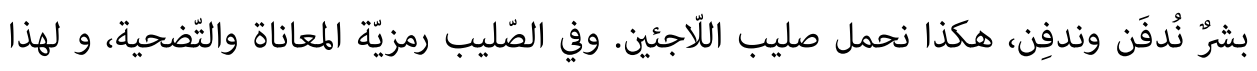

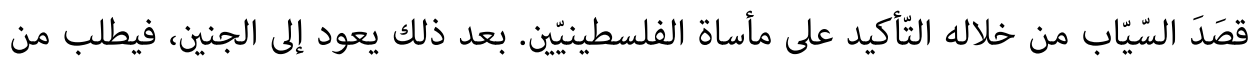

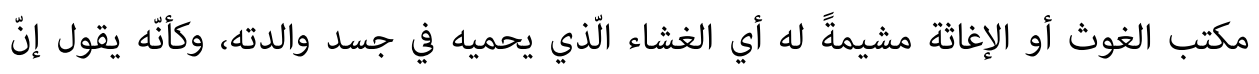

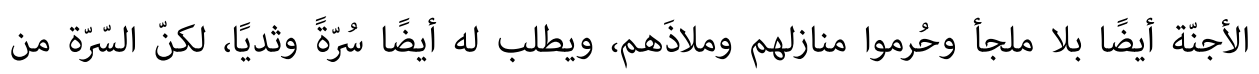

$$
\text { مطّاطٍ والثّدي من زجاج. }
$$

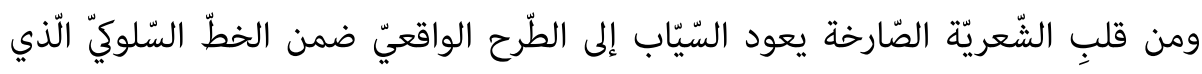

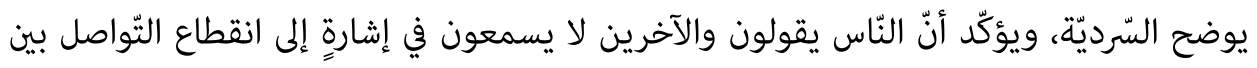

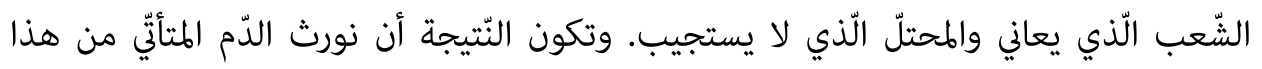

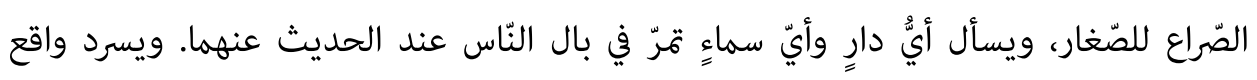

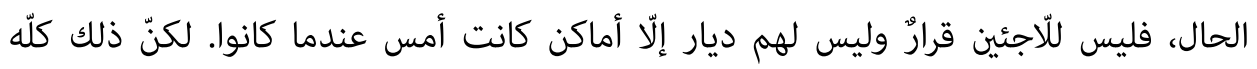

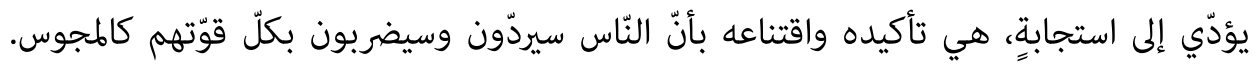

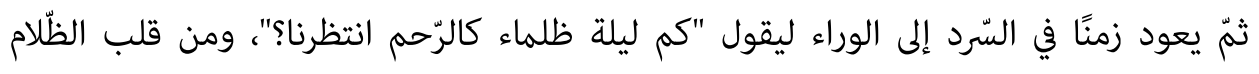

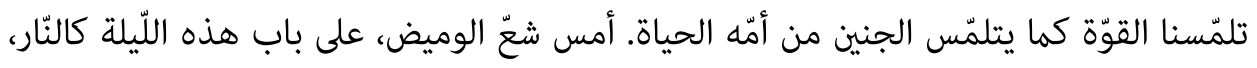

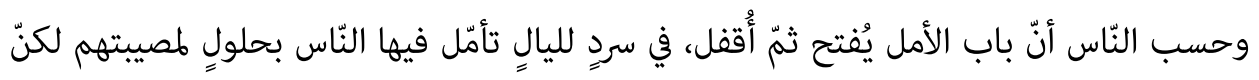


النّتيجة مل تكنْ كما أرادوا، أي كان الأمل استجابتهم لهذه المصيبة، لكنّ المصيبة بالمقابل تشتدّ بدلًا من أن تنتهي.

وفي نهاية القصيدة يتداخل النّمطان بشدّةٍ بين شعريّةٍ وسرديّة، فيقول إنّ اللّيل يجهض

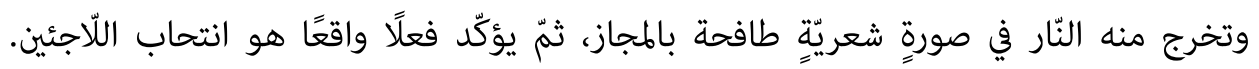
والنّار تركض وراء النّاس، ليعود ويذكّر بهجوم المغول، ويسأل عن خيول المعارك الغابرة، ليتساءل

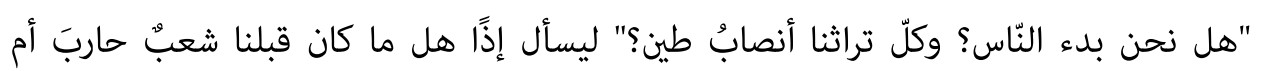
خيول، أو آمَنَ بالشّمس كالمجوس، أمَ أنّنا مل نرث إلّا طينًا.

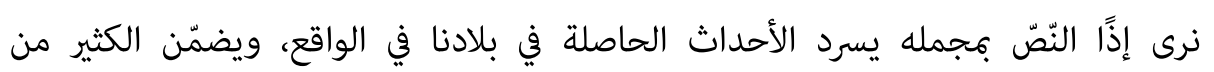

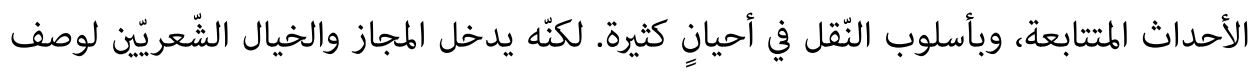

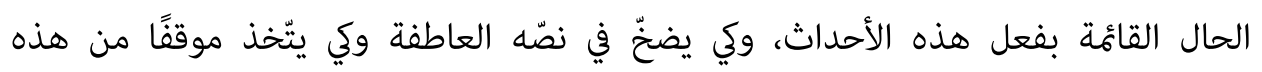
الأحداث أيضًا. يراوح النّصّ إذًا بين سردٍ وشعرِ، وبين واقعٍ وخيال.

\section{ץ-ب-القصص الدّينيّة والأحداث التّاريخيّة}

استعان بدر شاكر السّيّاب بأحداثٍ معروفة في التّاريخ كي يسرد أحداثًا مستجدّة، أو كي يضع

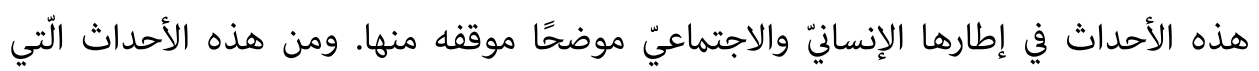

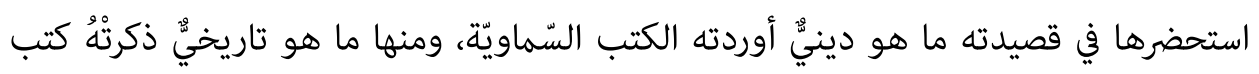
التّاريخ وتبرز تأثيراته حتّى يومنا هذا. وأبرز هذه القصص في النّصّ قصّة هابيل وقابيل، وقصّة السيّد المسيح، وقصّة المغول واحتلالهم المناطق العربيّة. وفي الواقع تأتي السّرديّة التّاريخيّة لدعم سرديّة النّصّ، ولتكون جزءًا منها. فنراه يُدخل

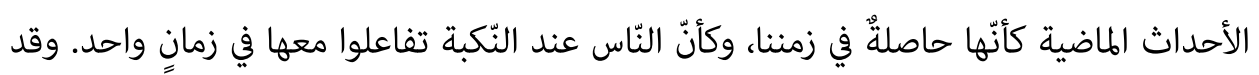

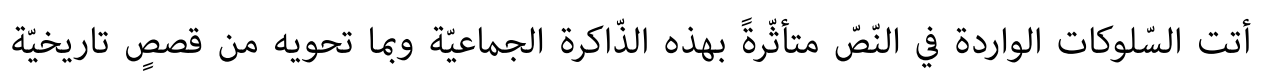
تدخل في تشكيل الوعي الجمعيّ والهويّة القوميّة. ومن الأمثلة البارزة حول ذلك سلوك

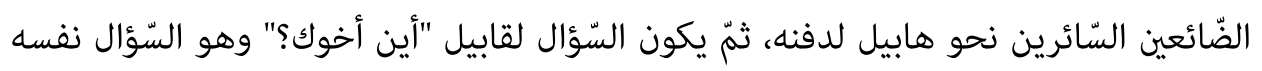

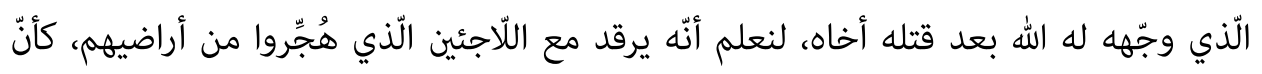
هابيل الّذي كان صوته بحسب الرّواية الدّينيّة في العهد القديم في الأرض كلّها تعبيرًا عن الظّلم 
الّذي قاساه(الإنجيل، العهد القديم، التّكوين، ع)، صار صوته في الأرض اليوم يعكس آلام اللّاجئين. وخلال سرده المعاناة الحاصلة يُدخِل المسيح في الحدث ليصير منه، ويأتي على ذكره غيرَ مرّةٍ. فمرّة يكون صليبه مكانًا لهابيل ليوضح السّيّاب عمق التّضحية الّتي يدفعها الإنسان حين يتعرّض

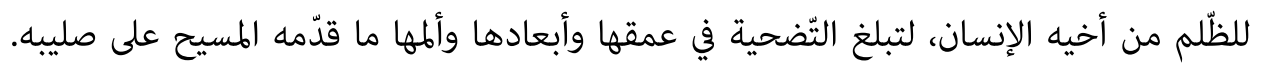

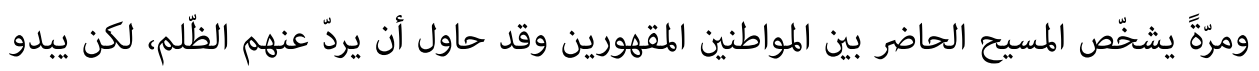
أنّ الطّوفان جرفه حتّى أوقف نزيفه، وهذا ما يجعل من السّيّد المسيح بحسب السّيّاب متفاعلًا

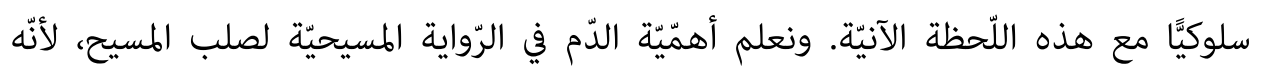
المضحّي بدمه وهو الّذي دفع دمه ليفدي به البشر، فيطرح إذًا السّيّاب الرّواية الواردة في الكتب الب البه السّماويّة ويذكرها على أنّها حاصلةٌ في العصر الحديث مع تعديلٍ في الأحداث، وهو تعديلٌ له له بله

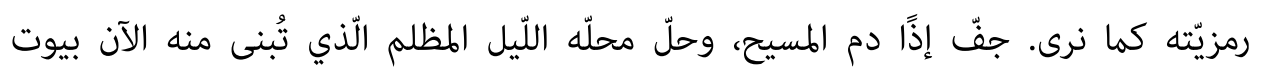

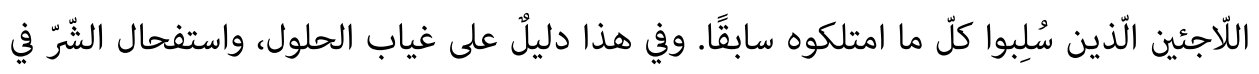
الأرض حتّى غياب المخلّص، فتكون استجابة المخلّص في هذا الزّمن غير كافيةٍ لإنقاذ شعبه اليوم

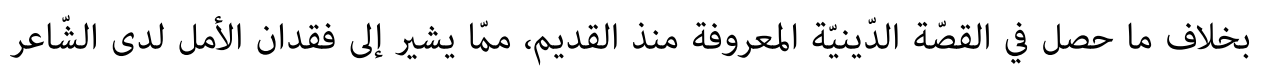

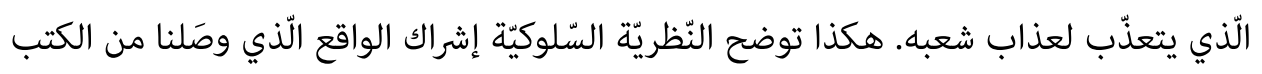

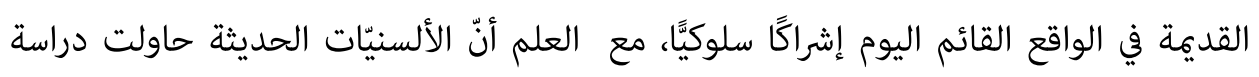

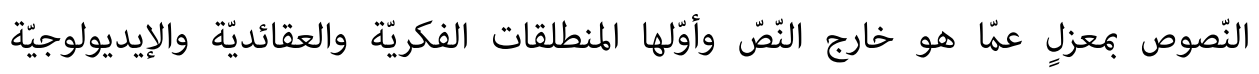
للمؤلّف (F). Feuillard, 235) أمّا في القصص التّاريخيّة، فيركّز على دور المغول في الحرب. فيسأل إن كان العدوّ في هذه

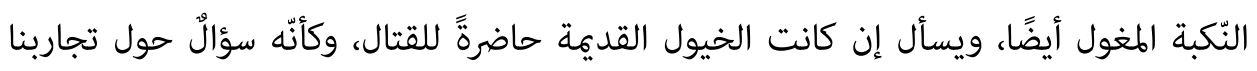

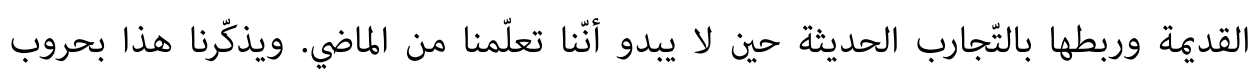

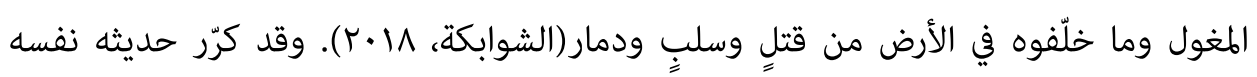

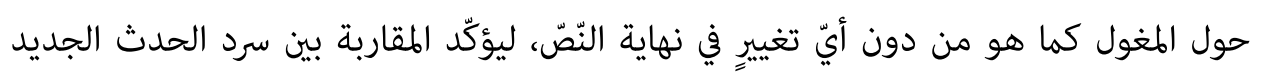

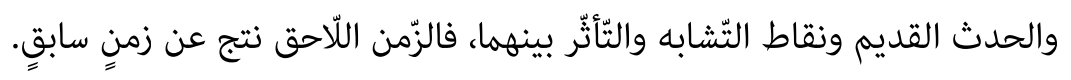


إذًا نلاحظ أنّ السّيّاب استند إلى أحداثٍ حاضرةٍ في ذاكرة النّاس ومعتقداتهم، وانطلق منها في

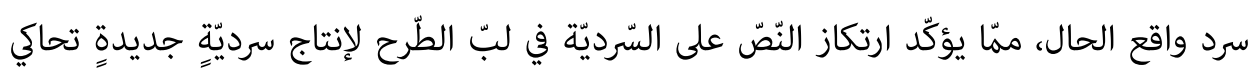
واقعًا مستجدَّا. r

إنّ أهمّ ما يجب طرحه حول الحوار تحديد المتحاورين، ووضع حدود الكلام ومفاصله، وذكر

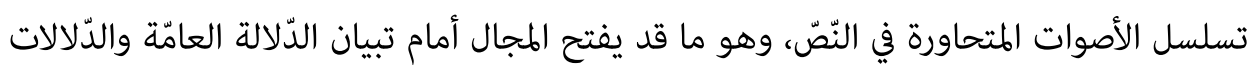
الخاصّة المندرجة تحتها. أوّلًا يظهر صوت الشّاعر الّذي يسأل القارئ ربّما إن رأى قافلة النّازحين الهاربين من الدّمار، ثمّ يظهر الصّوت الّذي يسأل قابيل عن أخيه، ثمّ يظهر صوت قابيل الّذي يؤَّدّ أنّ أخاه في خيام المشرّدين. ثمّ يفتح مجال الحوار للشّيء الغامض كي يسأل أو يؤكّد أو يطرح الحقائق، وللنّار التّي تهاجم وتركض خلف النّاس وتتكلّم بأعلى صوتها. ويعود صوت الشّاعر ويسأل عن السّنين الغابرة وعن الخيول القديمة التّي خاضت حروب العرب. هكذا إذًا تبرز الشّخصيّات في النّصّ وهي تتفاعل تباعًا مع الحدث وتهاثِ وتعايشه، وتطلق ردّات

$$
\text { فعلها حوله. }
$$

ويؤدّي الحوار دوره في توضيح الأحداث، وفي تفصيل التّفاعل مع كلّ حدث، كما يسهم في الإثارة إلى صوت السّارد الّذي يبرز في النّصّ على أنّه السّيّاب. والسّارد هو صاحب الصّوت السّرديّ، يقدّم الحكاية إلى مخاطَب، ويظهر ذلك في هذا النّصّ من خلال ضمير المخاطب. وهذا

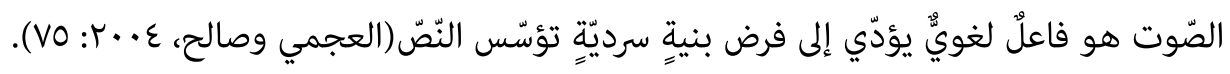

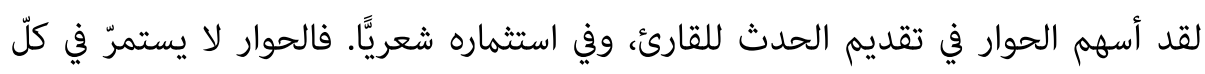
أجزاء القصيدة، بل يأتي متقطُعًا. فنجد النّّ ينقسم لمقاطع فيها من السّرديّة ما يمهّد لمقاطع

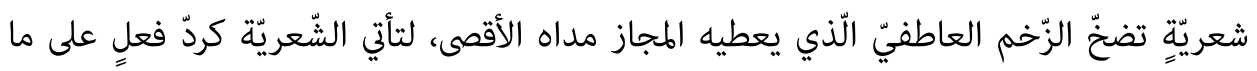

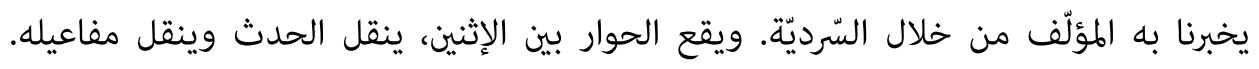
ويكون هذا الحوار منسجمًا مع التّقسيم السّلوكيّ الواقع في خطّين ممتدّين إلى جميع مفاصل 
نتائج البحث

في النّهاية، يصحّ أن يكون الكلام مفصّلًا أكثر على القصيدة انطلاقًا من مفاهيم أخرى كثيرةٍ، ويجوز البحث أكثر في الرّبط بين الواقعيّ والمتخيّل في نصوص بدر شاكر السّيّاب بشكلٍ عامّ، وفي مئي قصيدته "قافلة الضّياع" بشكلٍ خاصّ، ولكن هذا ما لا تتيحه مساحة البحث القصير المختصر.

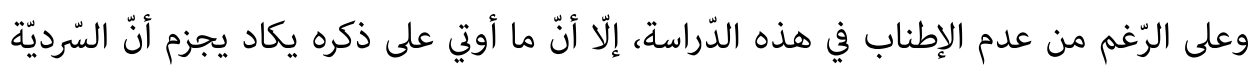

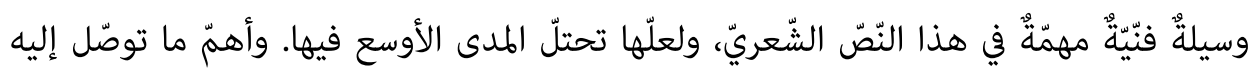
البحث هنا أنّ الشّاعر توسّل السّرديّة ليعبّر عن رفضه لواقعٍ قائمٍ هو الاعتداء الإسرائيليّ على هلى

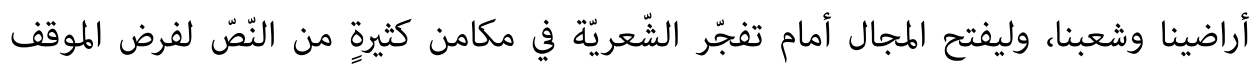
العاطفيّ الإنسانيّ. والسّرديّة تنهض على عنصرين أساسيّين هما الحكاية والخطاب، لتمثّل الحكاية الأفعال والوقائع والشّخصيّات والإطار الزّمانيّ / المكانيّ، في حين يتمثّل الخطاب في كيفيّة تقديم

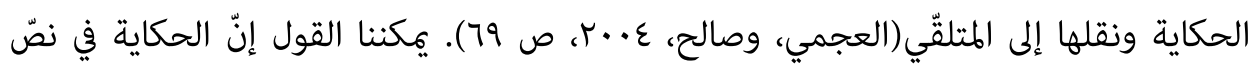
"قافلة الضّياع" واضحة المعام، ولعلّها هدفُ من أهداف المؤلّف، أمّا الخطاب، فهو إيقاعًا وقالبًا

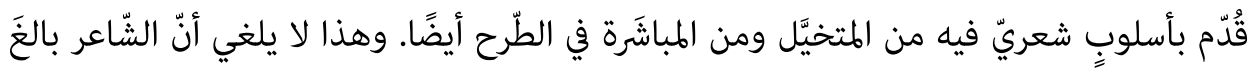
في ترجيح السّرديّة وإعطائها مقامًا قد لا يصحّ في كتابة القصائد، لأنّه ينقلنا من اللّحظة الشّعريّة

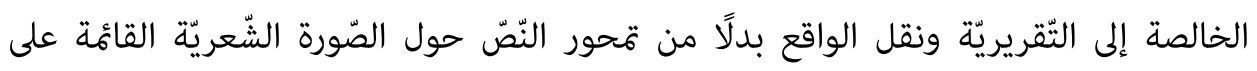

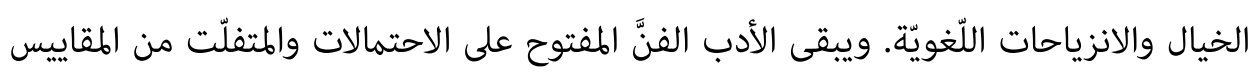

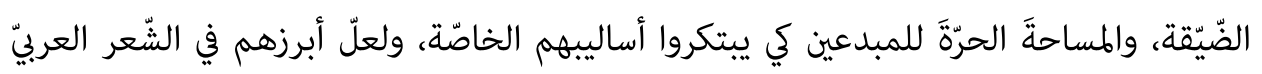
الحديث بدر شاكر السيّّاب.

المصادر والمراجع

أولاًا) الكتب السّماويّة

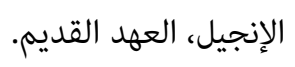

ثانياً) المصادر والمراجع العربيّة: 


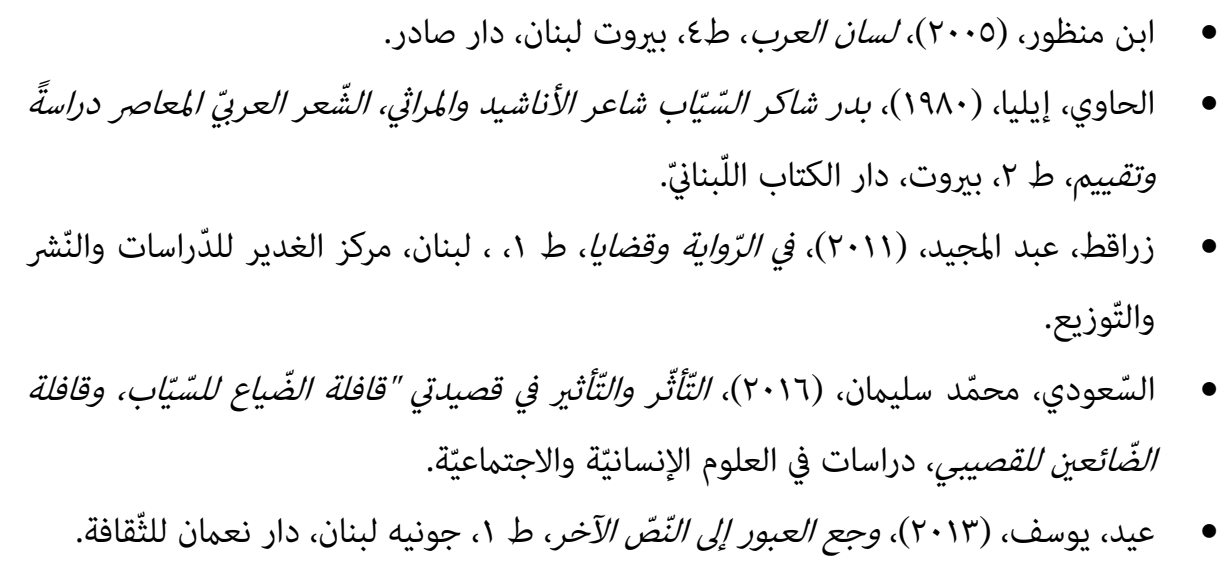

ثالثاً) المصادر والمراجع الأجنبيّة المعرّبة:

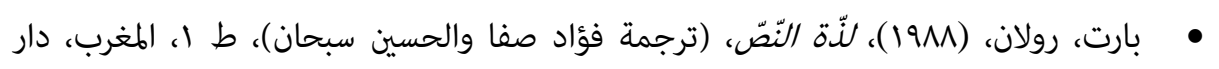
توبقال للنّشر.

\section{رابعاً) المصادر والهراجع الأجنبيّة:}

- Bloomfield, Leonard, (1933), Language, Los Angeles, The Library of the university of California.

- Feuillard, Colette, Liunquistique fonctionnelle et analyse textuelle, Paris, Universitee Paris Descartes.

$$
\text { خامساً) وقائع المؤتمرات والنّدوات: }
$$

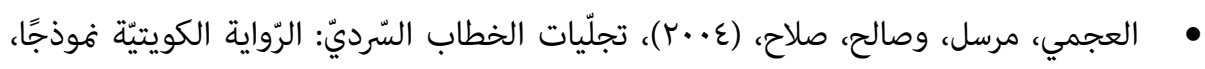

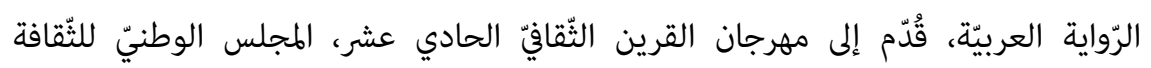

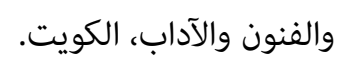

$$
\text { سادساً) المواقع الإلكترونيّة: }
$$

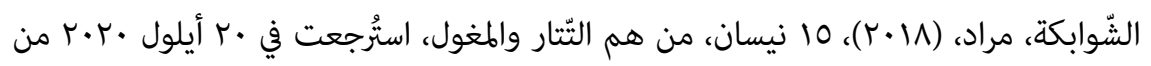

$$
\text { رابط موقع موضوع: - مرابه }
$$

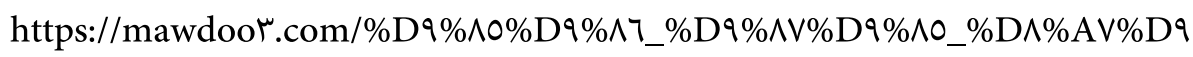

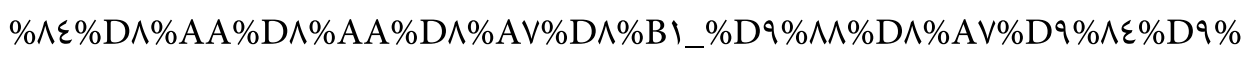

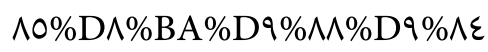




$$
\begin{aligned}
& \text { r- مؤلّفو موقع سطور، (19-19)، مr تشرين الثّاني، الشّعر /6لحميّ في الأدب العربيّ، }
\end{aligned}
$$

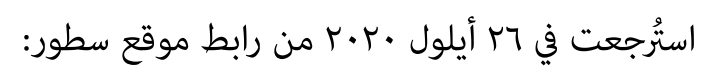

https://sotor.com/\%D8\%A7\%D9\%84\%D8\%B4\%D8\%B9\%D8\%B1-

\%D8\%A7\%D9\%84\%D9\%85\%D9\%84\%D8\%AD\%D9\%85\%D9\%8A-

\%D9\%81\%D9\%8A-\%D8\%A7\%D9\%84\%D8\%A3\%D8\%AF\%D8\%A8-

\%D8\%A7\%D9\%84\%D8\%B9\%D8\%B1\%D8\%A8\%D9\%8A

\section{References}

Holy books:

- The Bible, the Old Testament.

\section{Arabic Sources and References:}

- Ibn Manzur, 2005, Lisan Al Arab, 4th Edition, Beirut, Lebanon, Dar Sader.

- Al-Hawi, Elijah, 1980, Badr Shaker Al-Sayyab, Shaer Al Anashid Wal Marathi, Al She'er Al Arabi Dirasatan Wa Takyim, 2nd Edition, Beirut, Dar Al Kitab Al Lubnani.

- Zarqit, Abdel Majid, 2011, Fi Al Riwaya Wa Qadaya, 1st Edition, Lebanon, Al-Ghadeer Center for Studies, Publishing and Distribution.

- Saudi Muhammad Suleiman, 2016, Al Ta'athor Wa Al Ta'thir Fi Qasidati "Qafilat Al Daya Li Al-Sayyab, Wa Qafilat Al Dai'in Lel Qusaybi, Dirasat Fi Al Ouloum Al Insaniya Wa AL Ijtima'iya."

- Eid, Yusuf, 2013, Waja Al-Obour Li Al Nas Al Akhar, 1st Edition, Jounieh, Lebanon, Dar Noman Li Al Thaqafa.

\section{Arabized Foreign Sources and References:}

- Barth, R., 1988, Delight in the text, (translated by Fouad Safa and Hussein Subhan), Edition 1, Morocco, Toubkal Publishing House.

\section{New sources and references:}

- Bloomfield, Leonard, 1933, Language, Los Angeles, University of California Library.

- Feuillard, Colette, Liunquistique fonctionnelle and textuelle analysis, Paris, Universitee Paris Descartes. 


\section{Conferences and seminars:}

- Al-Ajmi, Mursal, and Saleh, Salah, 2004, Tajaliyat Al Khoutab Al Sardi: Al Riwaya AL Kuwaitiya Namouthajan, Al Riwaya Al Aarabiya, submitted to the eleventh Qurain Festival, the National Council for Culture, Arts and Literature, Kuwait.

\section{Website:}

- Shawabkeh, Murad, 2018, April 15, Man Hom Al Tatar Wal Maghoul, retrieved on September 20, 2020 from the Mawdoo3 website link:

- https://mawdoo3.com/\%D9\%85\%D9\%86_\%D9\%87\%D9\%85_\%D8\%A 7\%D9\%84\%D8\%AA\%D8\%AA\%D8\%A7\%D8\%B1_\%D9 \% 88\% D8\% A7\% D9\% 84\% D9\% 85\% D8\% BA\% D9\% 88\% D9\% 84

- Moualifou Mawqa' Soutoor, 2019, Teshrin Al Thani 25, Al She'er Al Malhami Fi Al Adab Al Arabi, retrieved on September 26, 2020, from the Soutoor website link:

- $\quad$ https://sotor.com/\%D8\%A7\%D9\%84\%D8\%B4\%D8\%B9\%D8\%B1\%D8\%A7\%D9\%84\%D9\%85\%D9\%84\%D8\%AD\% D9\% 85\% D9\% 8A\% D9\% 81\% D9\% 8A-\% D8\% A7\% D9\% 84\% D8\% A3\% D8\% AF\% D8\% A8-\% D8\% A7\% D9\% 84\% D8\% B9 \% D8\% B1\% D8\% A8\% $\mathrm{D} 9 \% 8 \mathrm{~A}$ 


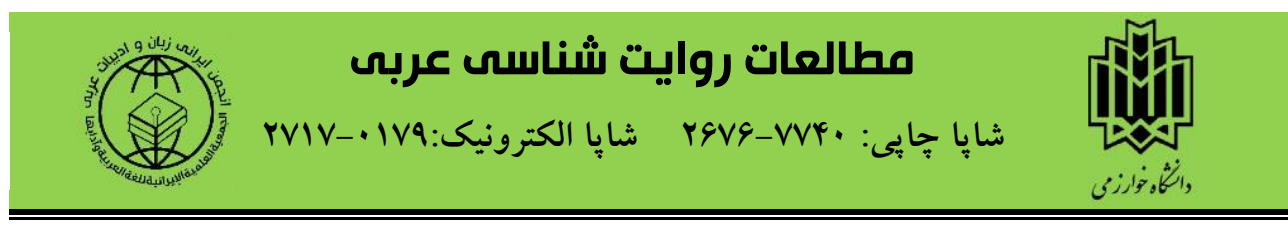

\title{
قصيده "قافله ضياع "بدرشاكر السياب؛ تركيب روايت يردازى و نظام شعرى عربى \\ lara.mallak@lau.edu.lb \\ راياناه:

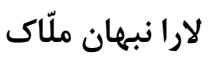

استاد مشاور زبانشناسى در دانشكاه آمريكايى لبنان

\begin{abstract}
جكيده

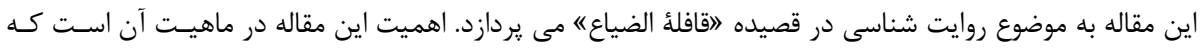

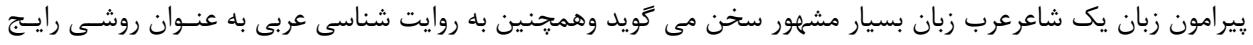

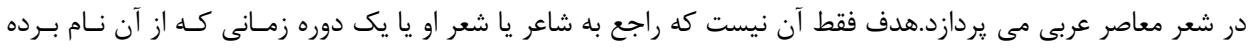

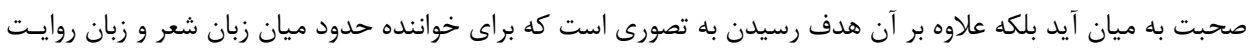

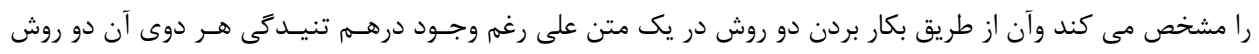

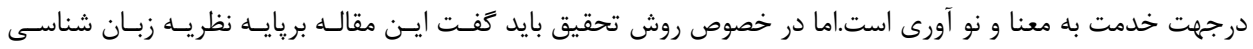

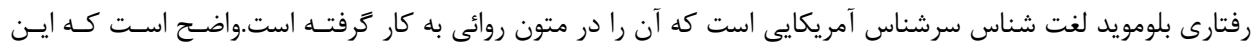

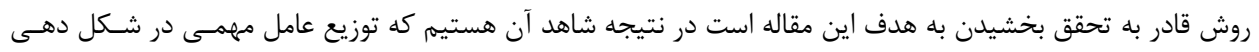

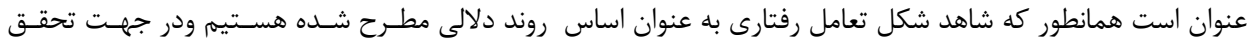

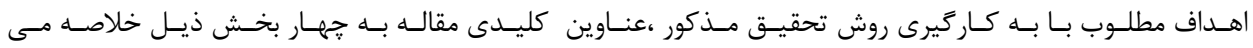

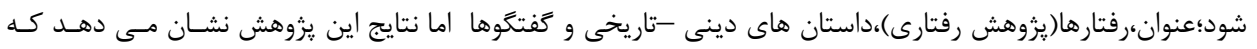

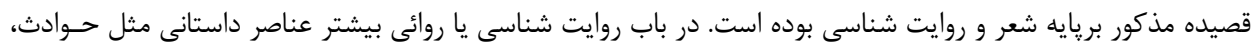

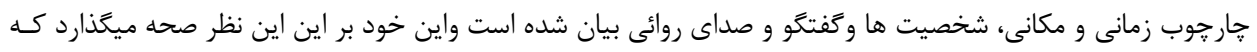

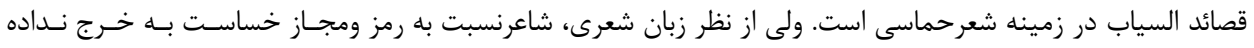

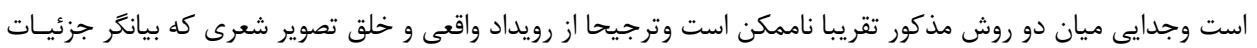

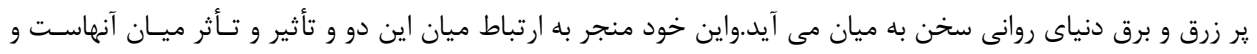

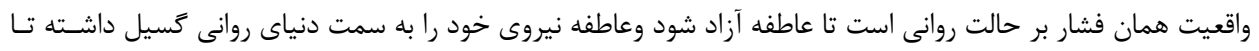

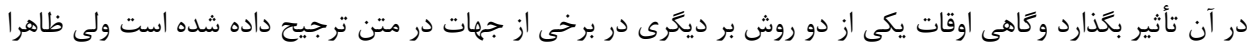

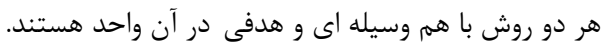

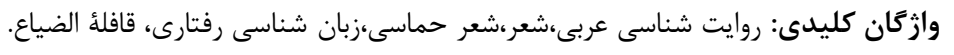

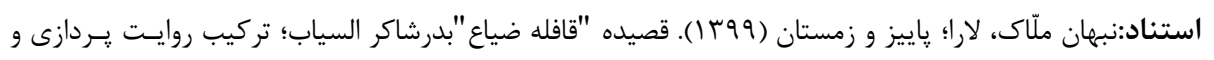

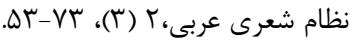




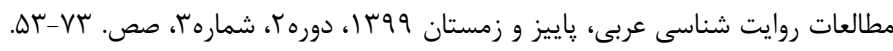

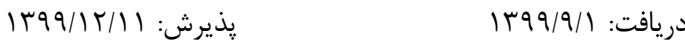

(C) دانشكده ادبيات وعلوم انسانى دانشخاه خوارزمى وانجمن ايرانى زبان وادبيات عربى بلى 